\title{
ВЛИЯНИЕ ПОЛИСИЛОКСАНДИКАРБОНОВОЙ КИСЛОТЫ НА СВОЙСТВА БУТАДИЕН-СТИРОЛЬНЫХ ЛАТЕКСОВ
}

\author{
(C) 2018 Д. В. Быковский ${ }^{1}$ А. В. Самотин ${ }^{1}$, М. С. Лавлинская ${ }^{1}$, \\ В. А. Кузнецов ${ }^{1}$, Л. А. Корыстина ${ }^{2}$, А. В. Сорокин ${ }^{1}$ \\ ${ }^{1}$ Воронежский государственный университет, Университетская пл., 1, 394018 Воронеж, Россия \\ ${ }^{2} О А О$ «Воронежсинтезкаучук», Ленинский пр., 2, 394014 Воронеж, Россия \\ e-mail:dr.v.kuznetsov@gmail.com
}

Поступила в редакцию 24.07.2018

\begin{abstract}
Аннотация. Изучено влияние добавок полисилоксандикарбоновой кислоты в рецептуры синтеза бутадиен-стирольных латексов. Определены коллоидно-химические свойства полученных латексов и физико-механические свойства их пленок. Установлено, что полученные латексы обладают рядом положительных свойств, таких как высокая агрегативная устойчивость, низкое пенообразование, а пленки на их основе имеют низкое водопоглощение и повышенную эластичность и прочность по сравнению с латексом, полученным по стандартной рецептуре.
\end{abstract}

Ключевые слова: полисилоксандикарбоновая кислота, бутадиен-стирольные латексы, латексные пленки.

DOI: https://doi.org/10.17308/kcmf.2018.20/574

\section{ВВЕДЕНИЕ}

Водные полимерные дисперсии, полученные методом эмульсионной полимеризации, широко используются в различных областях промышленности. Они применяются в качестве связующего при производстве красок, клеев, аппретирования текстильных изделий, получения различных покрытий и др. [1-4].

Как известно, процесс получения латексов связан с использованием различных поверхностно активных веществ, которые выполняют двоякую роль: стабилизатора эмульсии мономеров в процессе синтеза и обеспечивают стабильность готового латекса при переработке и хранении.

Однако количество эмульгатора, присутствующего в латексе может играть и отрицательную роль, так как с увеличением его дозировки резко возрастает пенообразующая способность, снижается прочность пленок, уменьшается адгезия к различным подложкам [5].

Поэтому представляет интерес разработка методов синтеза латексов с пониженным содержанием эмульгатора. Одним из таких путей является модификация эмульсионных систем введением различных стабилизаторов, позволяющих снизить содержание эмульгатора в рецептуре синтеза.
Кроме того, следует отметить, что снижение содержания эмульгатора в латексе приведет к снижению экологической нагрузки на окружающую среду, так как в большинстве случаев ПАВ являются бионеразлагаемыми продуктами [6].

В связи с чем цель работы состояла в изучении влияния добавок полисилоксандикарбоновой кислоты (ПСДК) в рецептуры синтеза бутадиен-стирольных латексов.

\section{ЭКСПЕРИМЕНТАЛЬНАЯ ЧАСТЬ}

Процесс синтеза латексов проводили в трехгорлой круглодонной колбе. Процесс полимеризации проводили при постоянном перемешивании и температуре $60 \pm 1{ }^{\circ} \mathrm{C}$. Предварительно готовили эмульсию мономеров (акриловая кислота, стирол и бутадиен) в водном растворе эмульгатора. В реактор, содержащий водный раствор инициатора персульфата калия (ПСК - 0.3 масс. ч.), подавали первую порцию мономерной эмульсии (10-15\% от общего объема), после чего реактор нагревали до заданной температуры. При температуре $60{ }^{\circ} \mathrm{C}$ в реактор подавали активатор метабисульфит натрия (МБС -0.05 масс. ч.).

Отбирались пробы для определения конверсии. Подача эмульсии мономеров происходила со 
скоростью 1.0 мл/мин. Реакцию проводили в атмосфере азота. Раз в полчаса в реактор добавляли порции активатора по 0.05 масс. ч.

На первом этапе работы полисилоксандикарбоновая кислота (ПСДК) вводился как дополнительный компонент рецептуры синтеза в количестве 0.5 до 1.5 масс. ч. при дозировке эмульгатора 3.0 масс. ч. в качестве эмульгатора использовали Disponil FES 32. Затем была произведена частичная замена эмульгатора на ПСДК, при этом дозировка эмульгатора снижалась с 3.0 до 2.0 масс. ч., количество ПСДК при этом увеличивалось от 0.5 до 1.0 масс. ч.

Поверхностное натяжение ( $\sigma)$ латексов определяли методом отрыва кольца на тензиометре ДюНуи (ГОСТ 20216-74, стандарт ИСО 1409-74) и рассчитывали по формуле:

$$
\sigma=K \cdot F,
$$

где $F$ - показание шкалы прибора в момент отрыва кольца от поверхности, мН/м; $K$ - калибровочный коэффициент, определяемый измерением поверхностного натяжения дистиллированной воды.

Устойчивость латекса к механическим воздействиям определяли методом Марона-Улевича. Испытание состоит в том, что латекс (75 мл) подвергается действию силы сдвига, создаваемой погруженным в него металлическим ротором, находящимся в контакте с полиэтилентелефталатной поверхностью. Измеряется количество коагулюма, образующееся в результате вращения ротора в течение определенного времени (5 мин) с фиксированными усилием (11.3 кг) и скоростью вращения (3000 об/мин). За меру устойчивости принимается количество образовавшегося коагулюма в \% масс:

$$
M=(W / S) \cdot 100,
$$

где $M$ - механическая устойчивость, $\% ; W$ - масса полученного коагулюма, г; $S$ - общая масса сухого остатка в латексе, г.

Гидродинамический диаметр латексных частиц, $D_{h}$, определяли с помощью анализатора размера частиц «Nanotrac 150» фирмы «Microtrac Inc.».

Способность латекса к пенообразованию изучали по следующей методике: в градуированную пробирку наливали 10 мл латекса, закрывали пробкой и встряхивали 10 раз. Затем измеряли объем полученной пены и оставляли пробирку в покое на 3 минуты. После этого повторно измеряли объем оставшейся пены.

Определение минимальной температуры пленкообразования проводили на термоградиентной установке «Термоспектр». После установления заданных температур на термоградиентной панели при помощи аппликатора на поверхность полиэтилентерефталатной пленки наносят тонкий слой испытуемой пробы. Пробу выдерживают до полного высыхания. Проводят отсчет расстояния $(L)$ в сантиметрах от начала измерительной шкалы на холодной части панели до границы между дискретной и непрерывной пленкой. Производят запись показаний цифровых индикаторов, расположенных на передней панели $\left(T_{1}, T_{2}, T_{3}\right)$.

Расчет МТП производят по формулам: при $L>10$ :

при $L \leq 10$ :

$$
\mathrm{MT \Pi}=T_{2}+\left(\left(T_{3}-T_{2}\right) / 10\right) \cdot(L-10)
$$

$$
\mathrm{MT \Pi}=T_{1}+\left(\left(T_{2}-T_{1}\right) / 10\right) \cdot L,
$$

где $T_{1}, T_{2}, T_{3}$ - температура левой, центральной, правой части панели, $L$ - расстояние от начала шкалы до границы между дискретной и непрерывной пленкой.

Для приготовления пленки латекс, предварительно профильтрованный, доводят до $40 \pm 1$-ной концентрации путем разбавления его водой. Отбирают 20 мл латекса и наливают на целлофан, предварительно смоченный водой и закрепленный на металлическом кольце. Диаметр кольца составляет 20 см. Латекс равномерным покачиванием распределяют на поверхности целлофана и оставляют для высушивания в сушильном шкафу при температуре $50 \pm 5{ }^{\circ} \mathrm{C}$ до тех пор, пока пленка не станет полностью прозрачной. Сухую пленку надрезают по периметру, смачивают водой и отделяют от целлофана. Остатки влаги с пленки удаляют фильтровальной бумагой. Пленку припудривают тальком для предотвращения слипания и выдерживают при комнатной температуре не менее часа.

Испытание физико-механических свойств заключается в растяжении образца пленки до разрыва и измерении нагрузки, вызывающей разрыв, удлинения, при котором происходит разрыв, и удлинения, остающегося после разрыва (ГОСТ 13522-78). Для определения этих показателей пользуются разрывной машиной «Tensometer 2020» производства фирмы «Alpha Technologies».

Набухание пленок в воде изучали по следующей методике: образцы латексов помещались на чашку Петри (в объеме 7 мл) и равномерно распределялись по её поверхности. Чашку с латексом помещали в сушильный шкаф до полного высушивания при температуре $45^{\circ} \mathrm{C}$. Высушенную 
пленку отделяли от поверхности чашки и вырезали из неё образцы $10 \times 10$ мм. Полученные квадратики взвешивали и помещали их в бюксы с водой. Набухшие пленки извлекали из воды, промокали фильтровальной бумагой и взвешивали через определенные промежутки времени, фиксируя привес воды на полимере.

Набухание пленки в \% определяется по следующей формуле:

$$
B=\left(m_{1}-m\right) \cdot 100 / m,
$$

где $B$ - процент водопоглощения пленки, $m_{1}-$ масса образца пленки после набухания; $m$ - масса образца пленки до набухания.

\section{ОБСУЖДЕНИЕ И РЕЗУЛЬТАТЫ}

Образцы бутадиен-стирольных латексов с различным количеством введенной ПСДК были получены радикальной эмульсионной полимеризацией. Для всех синтезированных латексов были определены некоторые коллоидно-химические свойства, численные значения которых представлены в табл. 1.

Определение механической стабильности проводилось при $\mathrm{pH} 2.5 \pm 0.2$, так как только в кислой среде обнаруживалась различие в значениях механической стабильности, при рН латексов 7.5 \pm 0.2 и выше все образцы имели высокую механическую устойчивость, и коагулюм отсутствовал. Как видно из представленных данных, при увеличении содержания модификатора полисилоксандикарбоновой кислоты в рецептуре синтеза от 0.5 до 1.0 масс. ч. механическая стабильность образцов латекса меняется незначительно, однако при дальнейшем увеличении дозировки ПСДК механическая стабиль- ность падает. При изменении рецептуры синтеза в сторону уменьшения количества эмульгатора до 2.5 масс. ч. с содержанием ПСДК 0.5 масс. ч. получены наилучшие результаты механической устойчивости латекса.

Пенообразующая способность латекса является одним из важнейших потребительских и промышленных качеств товарного продукта. В ходе исследования установлено, что пенообразующая способность резко уменьшается с увеличением концентрации вводимой ПСДК

Кроме того, следует отметить, что присутствие ПСДК в количестве 0.5-1.5 масс. ч. снижает минимальную температуру пленкообразования латекca, что, очевидно, связано с пластифицирующим действием модификатора на латексные глобулы. Данная характеристика очень важна для латексов, использующихся в производстве лакокрасочных материалов, где для более эффективного пленкообразования используются специальные добавки веществ, понижающих температуру пленкообразования (коалесцентов).

Данные о размере частиц, полученные на прибope «Nanotrac 150», представлены в табл. 1. Установлено, что при содержании эмульгатора 3.0 масс. ч. и увеличении дозировки ПСДК от 0.5 до 1.0 происходит постепенное снижение размера частиц, однако дальнейшее увеличение дозировки ПСДК приводит к обратному эффекту, что, по-видимому, требует более детального изучения механизма взаимодействия эмульгатора и модификатора.

Данные о физико-механических свойствах пленок, полученных из образцов латексов, представлены в табл. 2 .

Таблица 1. Коллоидно-химические свойства полученных образцов бутадиен-стирольных латексов, модифицированных ПСДК

[Table 1. Colloid-chemical properties of obtained SBLs modified with PSDA]

\begin{tabular}{|c|c|c|c|c|c|c|c|}
\hline No. & $\begin{array}{c}\text { ПСДК, м.ч./ } \\
\text { Disponil м.ч. } \\
\text { [PSDA, w.p./ } \\
\text { Disponil } \\
\text { w.p.] }\end{array}$ & $\begin{array}{c}\text { C.O., } \\
\% \\
\text { [D.R., } \\
\%]\end{array}$ & $\begin{array}{c}\sigma, \mathrm{MH} / \mathrm{M} \\
{[\sigma, \mathrm{mN} /} \\
\mathrm{m}]\end{array}$ & $\begin{array}{c}\text { Минимальная темпера- } \\
\text { тура пленкообразования, } \\
{ }^{\circ} \mathrm{C} \\
\text { [Min temperature of film } \\
\left.\text { formation, }{ }^{\circ} \mathrm{C}\right]\end{array}$ & $\begin{array}{c}\text { Механическая } \\
\text { стабильность, \% } \\
\text { (при рН 2.5) } \\
\text { [Mechanical } \\
\text { stability, \% } \\
\text { (pH 2.5)] }\end{array}$ & $\begin{array}{c}\text { Пенообразование, мл } \\
\text { (после встряхивания/ } \\
\text { через } 3 \text { мин) } \\
\text { [Foam formation, ml } \\
\text { (after shaking / after } 3 \\
\text { min)] }\end{array}$ & $\begin{array}{l}D_{h}, \\
\mathrm{HM} \\
{[\mathrm{Dh},} \\
\mathrm{nm}]\end{array}$ \\
\hline 1 & $0.0 / 3.0$ & 50.2 & 46.5 & 20 & 3.06 & $5.5 / 5.0$ & 181 \\
\hline 2 & $0.5 / 3.0$ & 50.4 & 47.0 & 15 & 2.54 & $1.5 / 1.5$ & 163 \\
\hline 3 & $1.0 / 3.0$ & 50.0 & 54.3 & 12 & 4.34 & $2.0 / 2.0$ & 149 \\
\hline 4 & $1.5 / 3.0$ & 51.0 & 55.0 & 8 & 7.50 & $2.0 / 1.0$ & 196 \\
\hline 5 & $0.5 / 2.5$ & 52.2 & 62.0 & 15 & 1.50 & $2.0 / 1.0$ & 207 \\
\hline 6 & $1.0 / 2.0$ & 45.1 & 58.2 & 12 & $\begin{array}{c}\text { Полная } \\
\text { коагуляция } \\
\text { [Full coagulation] }\end{array}$ & $2.0 / 0.0$ & 193 \\
\hline
\end{tabular}


Таблица 2. Физико-механические свойства пленок полученных из образцов латексов с различным соотношением содержания ПСДК/Disponil

[Table 2. Physical-mechanical properties of obtained film based on SBLs with different ratio of PSDA/Disponil]

\begin{tabular}{|c|c|c|c|}
\hline No. & $\begin{array}{c}\text { ПСДК, м.ч./Disponil, м.ч. } \\
\text { [PSDA, w.p./Disponil, w.p.] }\end{array}$ & $\begin{array}{c}\text { Напряжение при разрыве, мПа } \\
\text { [Rupture stress, mPa] }\end{array}$ & $\begin{array}{c}\text { Удлинение при разрыве, \% } \\
\text { [Breaking extension, \%] }\end{array}$ \\
\hline 1 & $0.0 / 3.0$ & 5.0 & 200 \\
\hline 2 & $0.5 / 3.0$ & 6.6 & 380 \\
\hline 3 & $1.0 / 3.0$ & 6.4 & 400 \\
\hline 4 & $1.5 / 3.0$ & \multicolumn{2}{|c|}{$\begin{array}{c}\text { Пленка pacтрескалась } \\
\text { [Film is decripitated] }\end{array}$} \\
\hline 5 & $0.5 / 2.5$ & $11.0 \quad$ & 196 \\
\hline 6 & $1.0 / 2.0$ & - & \\
\hline
\end{tabular}

Как видно из этих данных снижение содержания эмульгатора в присутствии 0.5 масс. ч. ПСДК приводит к увеличению прочности пленки и снижению ее эластичности, что можно объяснить оптимальным сочетанием соотношения дозировки эмульгатора и пластифицирующего действия ПСДК на полимерные глобулы, что привело к более полной коалесценции латексных глобул в процессе пленкообразования.

Данные по водопоглощению пленок, полученных из данных образцов латексов, представлены на рис. 1.

Как видно из этих данных введение ПСДК в дозировках 0.5 -1.0 масс. ч. приводит к существенному снижению водопоглощения пленок. Однако при увеличении дозировки ПСДК до 1.5 масс. ч. приводит к получению дефектных пленок что, по-видимому, объясняет повышение водопоглощающей способности образца за счет увеличения поверхности соприкосновения пленки с водой.

\section{ЗАКЛЮЧЕНИЕ}

Показано что введение ПСДК в рецептуру синтеза позволяет получить эффективные эмульгирующие системы для синтеза бутадиен-стирольного латекса, что выражается в снижении коагулюмообразования в процессе синтеза даже при снижении дозировки эмульгатора, узким распределением частиц по размерам, устойчивостью в процессе синтеза, низким пенообразованием, повышенной механической устойчивостью. Так же отмечается снижение минимальной температруры пленкообразования латекса, что повышает его технологичность при переработке. Пленки, полученные на основе модифицированных латексов, имеют низкое водопоглощение, повышенную эластичность и прочность.

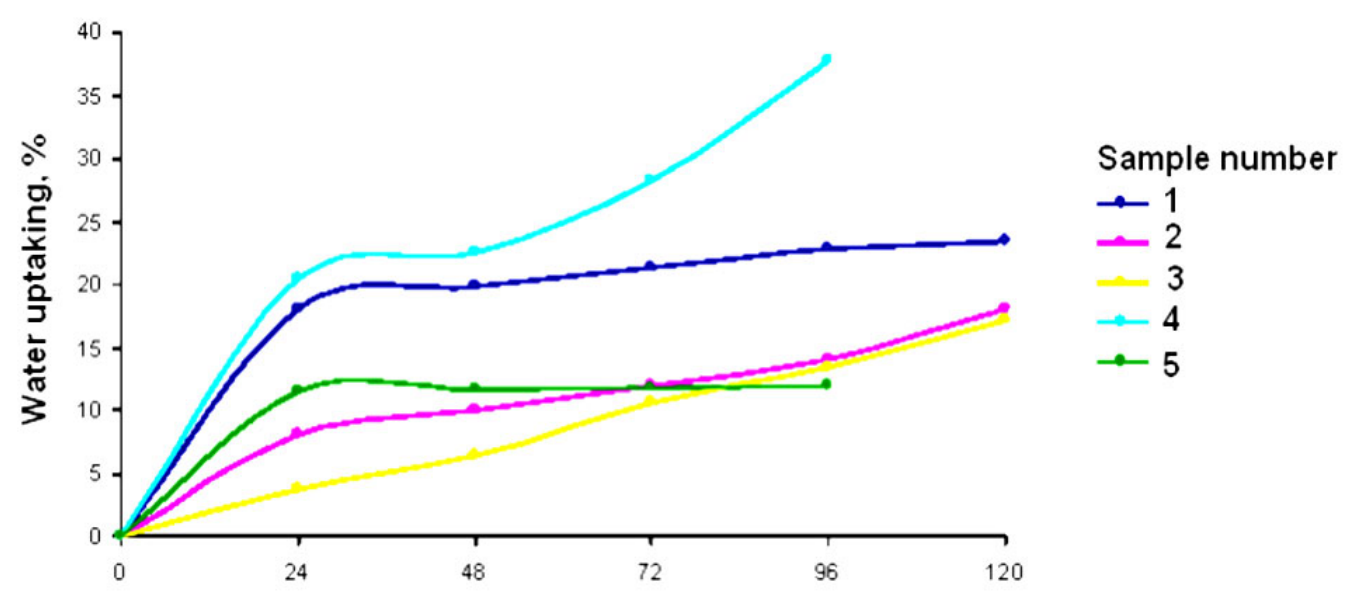

Time, h

Рис. 1. Водопоглощение пленок, полученных на основе образцов латексов с различным соотношением содержания ПСДК/Disponil

[Fig. 1. Water uptaking properties of the films, based on the latexes with different ratio of PSDA/Disponil] 


\section{СПИСОК ЛИТЕРАТУРЫ}

1. Грицкова И. А., Прокопов Н. И., Царькова М. С. и др. Новейшие достижения в области гетерофазной полимеризации: учебное пособие под ред. проф. С. А. Кедика. М.: ЗАО ИФТ, 2018, 352 с. $106 \mathrm{c}$.

2. Бахтина А. В. Дисс. ... канд. хим. наук. М.: 2018,

3. Вережников В. Н., Гринфельд Е. А. Синтез латексов: учебное пособие. Воронеж: ВНИИСК, 2005, $47 \mathrm{c}$.
4. Елисеева В. И., Иванчев С. С., Кучанов С. И. и др. Эмульсионная полимеризация и ее применение в промышленности. М.: Химия, 1976, 243 с.

5. Грицкова И. А., Жаченков С. В., Царькова М. С. и др. // Высокомолекулярные соединения. Серия Б, 2011, т. 53, № 11, c. 1994-2004.

6. Грицкова И. А., Шрагин Д. И., Левачев С. М. и др. // Тонкие химические технологии, 2016, т. 11, № 2, c. $5-16$.

\title{
THE INFLUENCE OF POLYSILOXANE DICABOXYLIC ACID ON STYRENE BUTADIENE LATEX PROPERTIES
}

\author{
(C) 2018 D. V. Bykovskiy ${ }^{1}$, A. V. Samotin ${ }^{1}$, M. S. Lavlinskaya ${ }^{1}$, V. A. Kuznetsov ${ }^{1}$, L. A. Korystina ${ }^{2}$, A. V. \\ Sorokin ${ }^{1}$ \\ ${ }^{1}$ Voronezh State University, 1 Universitetskaya pl., 394018 Voronezh, Russia \\ ${ }^{2} J S C$ «Voronezhsintezkauchuk», 2 Leninsky pr., Voronezh, Russia \\ e-mail:dr.v.kuznetsov@gmail.com
}

Received 24.08.2018

\begin{abstract}
The aim of this work is researching of influence of polysiloxane dicarboxylic acid (PSDA) on properties of styrene butadiene latex (SBL) and films based on it. PSDA is industry manufactured organic silicone water insoluble surfactant able to form stable oil-in-water emulsion in a presence of 0.1 weight parts. Synthesis of SBLs with different ratio of the emulsifiers Disponil FES 32 and PSDA was carried out by free radical emulsion polymerization with potassium persulfate initiator. Solid contents of SBLs is slightly depended of the emulsifier content mixture. Surface tension of modified SBLs is negligible higher in comparison to classical SBL. It was found via dynamic light scattering that size of the latex particles is decreased in a presence of 3.0 weight parts of Disponil FES 32 and 0.5-1.0 weight parts of PSDA, and growth of the latter content leads to particle size increasing. Mechanical stability evaluated as coagulum formation, and foam formation ability of SBLs also improved in a presence of 0.5-1.0 weight parts of PSDA. Latex films obtained from the modified by PSDA SBLs possess better mechanical properties. It should be noted that water sorption properties of modified latex films (Fig.1) are dramatically declined for SBLs prepared with PSDA use due to high hydrophobicity of organic silicone compounds. To sum up, presence of 0.5-1.0 weight parts of PSDA in initial polymerization emulsion leads to improving of some properties of SBL and films based on it such as mechanical stability, foam formation ability of latexes and water sorption ability of modified SBL films.
\end{abstract}

Keywords: polysiloxane dicarboxylic acid, styrene-butadiene latex, latex films.

DOI: https://doi.org/10.17308/kcmf.2018.20/574

\section{REFERENCES}

1. Grickova I. A., Prokopov N. I., Tsarkova M. S., et al. Noveishie dostizheniya $v$ oblasti geterofaznoy polymerizatsii: uchebnoe posobie pod red. prof. Kedik S. A. [The Newest Achievements in a Range of Emulsion Polymerization]. Moscow, ZAO IFT Publ., 2018, 352 p. (in Russ.)

2. Bakhtina A. V. Diss...cand. chem. sci., Moscow, 2018, 106 p. (in Russ.)

3. Verezhnikov V. N., Grinfeld E. A. Sintez lateksov: uchebnoe posobie [Synthesis of Latexes]. Voronezh,VNIISK Publ., 2005, 47 p. (in Russ.)
4. Eliseeva V. I., Ivanchev S. S., Kuchanov S. I., et al. Emulsionnaya polimerizatsiya I ee primenenie $v$ promyshlennosti [Emulsion Polymerization and it Application in Industry]. Moscow, Khimiya Publ., 1976, 243 p. (in Russ.)

5. Gritskova I. A., Zhachenkov S. V., Tsar'kova M. S., et al. Polym. Sci. Ser. B, 2011, vol. 53, no. 11-12, pp. 568577. DOI: $10.1134 / \mathrm{S} 1560090411110029$

6. Gritskova I. A., Shragin D. I., Levachev S. M., et al. Fine Chemical Technologies, 2016, vol. 11, no. 2, pp. 5-16. (in Russ.) 
Быковский Дмитрий Владимирович - аспирант кафедры высокомолекулярных соединений и коллоидной химии, Воронежский государственный университет; тел.: +7(951) 8713126, e-mail: nasredinne@mail.ru

Самотин Александр Викторович - магистрант 1 года обучения кафедры высокомолекулярных соединений и коллоидной химии, Воронежский государственный университет

Лавлинская Мария Сергеевна - к. х. н., м. н. с. базовой кафедры ЭФКО «Молекулярная биотехнология», Воронежский государственный университет; тел.: +7(950) 7585216; e-mail: maria.lavlinskaya@gmail.com

Кузнецов Вячеслав Алексеевич - Д. х. н., доцент, профессор кафедры высокомолекулярных соединений и коллоидной химии, Воронежский государственный университет; тел.: +7(920) 4523733; e-mail: dr.v.kuznetsov@gmail.com

Корыстина Людмила Андреевна - к. х. н., в. н. с. $\mathrm{OAO}$ «Воронежсинтезкаучук»

Сорокин Андрей Викторович - магистрант второго года обучения кафедры высокомолекулярных соединений и коллоидной химии, Воронежский государственный университет
Dmitriy V. Bykovskiy - post-graduate student of Macromolecules Compounds and Colloid Chemistry Department, Voronezh State University; tel.: +7(951) 8713126, e-mail: nasredinne@mail.ru

Alexandr V. Samotin - master student of the first year education of Macromolecules Compounds and Colloid Chemistry Department, Voronezh State University

Maria S. Lavlinskaya - Cand. Sci. (Chem.), Junior Researcher of Molecular Biotechnology Department, Voronezh State University; tel.: +7(950) 7585216; email: maria.lavlinskaya@gmail.com

Vyacheslav A. Kuznetsov - Dr. Sci. (Chem.), Professor of Macromolecules Compounds and Colloid Chemistry Department, Voronezh State University; tel.:+7(920) 4523733; e-mail: dr.v.kuznetsov@gmail. com

Lyudmila A. Korystina - Cand. Sci. (Chem.), Senior Researcher of JSC «Voronezhsintezkauchuk»

Andrey V. Sorokin - master student of the second year education of Macromolecules Compounds and Colloid Chemistry Department, Voronezh State University 